\title{
Steroid Hormone Receptor
}

National Cancer Institute

\section{Source}

National Cancer Institute. Steroid Hormone Receptor. NCI Thesaurus. Code C18108.

Steroid hormone receptors are proteins found in either the cytoplasm or nucleus of eukaryotic cells which bind to and regulate the transcription of DNA under the regulation of steroid hormones. These proteins are the first receptors assigned to the steroid/thyroid/retinoid nuclear receptor superfamily, a group of transcription factors whose activity is regulated by small lipid-soluble molecules. 